\title{
ARTIGOS
}

\section{REVISÃO DE LITERATURA: O CONCEITO DE GESTÃO ESCOLAR}

\author{
IVANA CAMPOS OLIVEIRA' \\ IONE VASQUES-MENEZES"
}

\section{RESUMO}

O artigo pretende contribuir para a sistematização do tema gestão escolar, identificando a existência ou não de lacunas na literatura sobre o assunto, analisando as publicações e a evolução do conceito de gestão. É uma revisão de teses e artigos nacionais e internacionais indexados nas bases de dados SciELO e Pepsic de 2005 a 2015. A referência teórica é baseada em autores como Libâneo (2007), Lück (2007), Paro (2008) e Vasconcellos (2009). A pesquisa permitiu a percepção de que inicialmente o conceito de gestão escolar apontou para os aspectos mais administrativos da função e que, ao longo do tempo, buscou o conteúdo mais pedagógico e político. Observou-se também que houve um aumento da pesquisa nos últimos anos sobre a gestão escolar, com ênfase na gestão democrática da escola.

GESTÃO ESCOLAR • REVISÃO DE LITERATURA • PESQUISA

\section{LITERATURE REVIEW: THE CONCEPT OF SCHOOL MANAGEMENT}

\section{ABSTRACT}

The article intends to contribute to the systematization of the topic school management, identifying the existence or not of gaps in the literature on the subject, analyzing the publications and the evolution of the concept of management. It is a review of national and international doctoral dissertations and articles indexed in SCIELO and PEPSIC databases from 2005 to 2015. The theoretical

Universidade Salgado de Oliveira (Universo), Săo Gonçalo (RJ), Brasil; ivanaaraujocampos@ yahoo.com.br

Universidade Salgado de Oliveira (Universo), São Gonçalo (RJ), Brasil; vasquesmenezes@ framework is based on authors such as Libâneo (2007), Lück (2007), Paro (2008), and Vasconcellos (2009). Research findings indicate that, whereas initially the concept of school management pointed to the more administrative aspects, over time it encompassed more pedagogical and political content. It was also observed that there has been an increase in the research on school management over the last years, with emphasis on the democratic management of schools.

SCHOOL MANAGEMENT • LITERATURE REVIEW • RESEARCH 


\section{REVUE BIBLIOGRAPHIQUE: LE CONCEPT} DE GESTION SCOLAIRE

\section{RÉSUMÉ}

Cet article aspire contribuer à la systématisation de la question de la gestion scolaire, en identifiant, à partir de l'analyse de publications et de l'évolution du concept de gestion, s'il existe ou non des lacunes dans la littérature à ce sujet. Ce travail passe en revue des thèses et des articles nationaux et internationaux, indexés dans les bases de données SciELO et Pepsic, publiés entre 2005 et 2015. La cadre théorique s'appuye sur des auteurs comme Libâneo (2007), Lück (2007), Paro (2008) et Vasconcellos (2009). La recherche a permis de percevoir que si, au départ, le concept de gestion scolaire mettait l'accent sur des aspects plus administratifs de la fonction, au fil du temps, il s'est tourné vers des contenus plus pédagogiques et politiques. En outre, on a pu observer qu'il y avait eu, ces dernières années, un foisonnement de la recherche sur la gestion scolaire et, plus particulièrement, sur la gestion démocratique de l'école.

GESTION DE L'ÉCOLE • REVUE BIBLIOGRAPHIQUE • RECHERCHE

El artículo pretende contribuir para sistematizar el tema gestión escolar, identificando la existencia o no de lagunas en la literatura sobre el tema, analizando las publicaciones y la evolución del concepto de gestión. Se trata de una revisión de tesis y artículos nacionales e internacionales indizados en las bases de datos SciELO y Pepsic de 2005 a 2015. La referencia teórica se basa en autores como Libâneo (2007), Lück (2007), Paro (2008) y Vasconcellos (2009). La investigación permitió percibir que inicialmente el concepto de Gestión Escolar abarcaba los aspectos más administrativos de la función y que, a lo largo del tiempo, buscó el contenido más pedagógico y político. Se observó también que hubo un aumento de la investigación en los últimos años sobre la gestión escolar, con énfasis en la gestión democrática de la escuela. 

escolar, as pesquisas deixam uma lacuna a ser preenchida, sobre o cotidiano da gestão e dos sujeitos que compõem a comunidade escolar. Este artigo apresenta uma revisão de pesquisas publicadas a partir da discussão do conceito de gestão escolar. Objetivou-se identificar a existência ou não de lacunas na literatura sobre o tema em estudo, realizando uma análise das principais publicações dos últimos dez anos e da evolução do conceito de gestão.

Estudos anteriores, como os de Gracindo e Wittmann (2001), Pereira e Andrade (2005), e Souza (2006), que trazem revisões de literatura sobre o tema gestão escolar revelam uma crescente preocupação nas produções nacionais, desde o final da década de 1990, com a identidade do administrador escolar, a reconstrução de seu perfil e as novas exigências da função. A partir da promulgação da Constituição de 1988 (BRASIL, 1988) e das eleições para diretor, o desenvolvimento de pesquisas sobre direção escolar se acentuou devido ao processo de democratização da escola e da busca pela autonomia. Os estudos mostram também que pesquisas sobre gestão democrática foram responsáveis por mais de $31 \%$ dos trabalhos de mestrado e doutorado no período de 1981 até 2001. Souza (2006) complementa, em seu levantamento bibliográfico, que os estudos sobre o diretor escolar foram destaque entre 
as décadas de 80 e 90 , representando mais de $28 \%$ das pesquisas de pós-graduação stricto sensu na área de administração escolar. Também mereceram destaque os estudos desses autores sobre o conselho escolar, respondendo por quase 17\% da produção no período posterior a 1990. Segundo eles, de 1991 até o final da década de 90, as políticas educacionais e a formação dos profissionais da educação, assim como a gestão escolar, tornaram-se temas prioritários nos estudos teóricos e empíricos de pesquisadores brasileiros. Embora não tenham sido encontrados estudos literários internacionais que tratam do tema gestão escolar nos últimos anos, autores como Sander (2007) apresentam o destaque que vem sendo dado internacionalmente às pesquisas acadêmicas sobre autonomia e descentralização da gestão escolar.

Este artigo, que se justifica pela necessidade de um maior aprofundamento das teorias dos autores encontrados, analisa suas contribuições e destaca as visões acerca do tema estudado, avançando assim no domínio e na sistematização do que está sendo produzido nessa área do conhecimento. Foi organizado em três momentos: estudo do referencial teórico sobre gestão, levantamento dos artigos e teses nacionais dos últimos dez anos, e a análise da evolução do tema gestão escolar. A intenção foi construir um referencial teórico que possa subsidiar a análise da gestão escolar em futuros estudos sobre o tema.

\section{GESTÃO E GESTÃO ESCOLAR}

Originário do latim gestione, o conceito de gestão refere-se à ação e ao efeito de gerir ou de administrar. Muitas concepções foram dadas para o tema no decorrer dos anos. Andrade (2001), no Dicionário de sinônimos da língua portuguesa, alerta que, embora a palavra portuguesa gestão, em seu sentido original, expresse a ação de dirigir, de administrar e de gerir a vida, os destinos, as capacidades das pessoas, uma parcela da sociedade compreende gestão como funções burocráticas, destituídas de uma visão humanística, e como uma ação voltada à orientação do planejamento, da distribuição de bens e da produção desses bens.

Segundo Garay (2011), gestão é o processo de dirigir a organização e, a partir daí, tomar decisões levando em consideração as demandas do ambiente e os recursos disponíveis. Garay explica ainda que gestão está relacionada ao chamado processo administrativo, definido por Fayol, em 1916, como o ato de planejar, organizar, dirigir e controlar os recursos da empresa, para que os objetivos sejam alcançados.

Inicia-se, a partir daqui, o estudo específico do conceito de gestão escolar. Será utilizado o termo gestão escolar em detrimento de administração escolar, partindo-se da compreensão de que são termos distintos, ao se tratar de educação. Para Santos Filho (1998), administração traz, no caso da educação, uma concepção técnica, hierarquizada e frag- 
mentada, baseada no poder e na autoridade. $O$ autor prefere a utilização de gestão escolar, que leva ao conceito de compartilhamento de ideias, participação de todos no processo de organização e funcionamento da escola. Bordignon e Gracindo (2000) compreendem que gerenciar uma escola é diferente de gerenciar outras organizações sociais, devido à sua finalidade, estrutura pedagógica e às relações internas e externas.

Libâneo (2007) também prefere a utilização do termo gestão escolar quando se associa à escola, e trabalha com a concepção sociocrítica de gestão escolar. Nessa concepção, a gestão escolar também é engendrada como um sistema que agrega pessoas, "considerando o caráter intencional de suas ações e as interações sociais que estabelecem entre si e com o contexto sócio-político, nas formas democráticas de tomada de decisões" (LIBÂNEO, 2007, p. 324). Compreende-se que o processo de tomada de decisões dá-se coletivamente, possibilitando aos membros do grupo discussão e deliberação conjunta. Assim, o gestor escolar, na dimensão política, exerce o princípio da autonomia, que requer vínculos mais estreitos com a comunidade educativa, os pais, as entidades e organizações paralelas à escola. Gestão é então a atividade pela qual se mobilizam meios e procedimentos para atingir os objetivos da organização e envolve aspectos gerenciais e técnico-administrativos.

O princípio da gestão democrática inclui a participação ativa de todos os professores e da comunidade escolar como um todo, de forma a garantir qualidade para todos os alunos. O processo de gestão deve coordenar a dinâmica do sistema de ensino como um todo e de coordenação nas escolas em específico. Indo além, discute a importância da articulação das diretrizes e políticas educacionais públicas, e ações para implementação dessas políticas e dos projetos pedagógicos das escolas. Esse projeto deve estar compromissado com os princípios da democracia e com um ambiente educacional autônomo, de participação e compartilhamento, com tomada conjunta de decisões e efetivação de resultados, acompanhamento, avaliação e retorno de informações. Por fim, precisa apresentar transparência através da demonstração pública de seus processos e resultados (LÜCK, 2007).

Paro (2008) apresenta a ideia de administração escolar inspirada na cooperação recíproca entre os homens. Defende que a escola precisa de um novo trabalhador que busque o coletivo, e que seja gerida sem os constrangimentos da gerência capitalista, em decorrência do trabalho cooperativo de todos os envolvidos no processo escolar, em direção ao alcance de seus objetivos verdadeiramente educacionais. Vasconcellos (2009) apresenta a proposta de uma direção com a responsabilidade de elo integrador e articulador dos vários segmentos, internos e externos, da escola. Segundo Vasconcellos (2009), cabe ao diretor fazer a gestão das atividades, para que o projeto da escola aconteça a contento. Para ele, um grande perigo é o diretor se prender à tarefa de "fazer a escola 
funcionar", deixando de lado seu sentido mais profundo de gestão escolar. Entende-se que se trata não de um papel puramente burocrático-administrativo, mas sim de uma tarefa de articulação, de coordenação e intencionalidade, que, embora suponha os aspectos administrativos, vincula essencialmente o diretor à gestão pedagógica da escola.

Burak e Flack (2011) também associam gestão escolar a ações coletivas e democráticas, com a divisão de responsabilidades individuais, que devem ser pautadas num projeto maior, que congrega todos os membros da equipe escolar em torno de objetivos, metas, decisões e compromissos comuns. Acentua-se o caráter político democrático, que, segundo o autor, deve permear a cultura organizacional das instituições escolares. Já Cattani e Hozlmann (2011) preferem não delimitar esse tipo de gestão à gestão escolar e a denominam gestão participativa. Acreditam que, na gestão participativa, os trabalhadores estão investidos, diretamente ou por delegação, da capacidade de decisão na organização do trabalho, eventualmente nos processos administrativos e comerciais, e mais raramente na condução geral da empresa.

Vários autores - Santos Filho (1998), Bordignon e Gracindo (2000), Libâneo (2007), Lück (2007), Paro (2008), Vasconcellos (2009), Burak e Flack (2011), e Cattani e Hozlmann (2011) - defendem uma gestão escolar democrática em que a coletividade possa se manifestar através da participação efetiva nas decisões e ações da escola. Participação e autonomia são, segundo esses teóricos, fatores fundamentais para que a escola construa um espaço de gestão escolar democrática. A partir desse conceito, compreendem também que a figura do diretor muda do administrador para o líder democrático, que busca ser um integrador da comunidade escolar, almejando ser também um conciliador das diversas opiniões e anseios desse grupo.

\section{GESTÃO DEMOCRÁTICA E AUTONOMIA DA ESCOLA}

Borges (2004, p. 78) analisa que "nas últimas duas décadas tem se observado um movimento de dimensões mundiais rumo a padrões descentralizados de gestão dos sistemas educacionais". Observa que reformas educacionais foram implementadas em âmbito mundial, tanto nos países em desenvolvimento como nos desenvolvidos, para os quais os governos vêm buscando dar autonomia administrativa e financeira, através da participação da comunidade nos colegiados e outras formas de gestão representativa nas escolas, passando-se, assim, o poder de decisão para essas comunidades escolares. Esse autor relata também que na América Latina as agências de financiamento, especialmente o Banco Mundial, tiveram papel fundamental nessas mudanças, através de seus programas que cobravam ajustes estruturais em âmbito educacional. 
Whitty e Power (2000) destacam que, em alguns países, como Austrália, Estados Unidos, Grâ-Bretanha e Nova Zelândia, os partidos conservadores e os think tanks foram responsáveis diretos por essas mudanças em âmbito educacional, com as quais na verdade se buscava a redução dos custos e a transferência das responsabilidades para professores, gestores e comunidade escolar em geral. Por isso, tanto nos países de língua inglesa quanto nos latino-americanos, o empoderamento da comunidade se tornou uma tendência hegemônica dentro da onda de governança escolar.

Cunha (1991) analisa que, dentro dessa política de autonomia orquestrada pelas agências financiadores em países menos desenvolvidos, e especialmente no Brasil, o Estado propaga a descentralização administrativa, financeira e pedagógica e atribui maior autonomia às escolas. Porém, essa suposta descentralização vem acompanhada de diversos processos que tratam da padronização dos procedimentos administrativos e pedagógicos com a finalidade de garantir a redução dos custos e a redefinição dos gastos, não se abrindo mão de forma alguma das políticas controladoras.

Bordignon e Gracindo (2000) entendem que essa autonomia não se faz apenas com políticas que buscam criar espaços e formas de organização da escola onde se construirá a gestão democrática; o que se deve buscar é a redefinição de conceitos e formas democráticas dentro da escola, discutindo-se o formato da democracia que desejamos através da oportunização da participação dos diferentes segmentos do contexto escolar. No Brasil, essa autonomia se iniciou no final da década de 80 , ganhando força a partir da Constituição de 1988 (BRASIL, 1988) e da Nova Lei de Diretrizes e Bases da Educação Nacional de 1996 (LDB/96) (BRASIL, 1996), que instituíram a gestão democrática escolar como princípio (ROCHA, 2009).

\section{MÉTODO}

Com o objetivo de oferecer um panorama da evolução da produção científica sobre gestão escolar, realizou-se uma revisão de literatura de publicações nacionais e internacionais. Para Cardoso, Alarcão e Antunes (2010), a revisão de literatura permite uma análise minuciosa dos trabalhos publicados num determinado período, facilitando a sistematização do tema. A intenção foi, então, construir um referencial teórico que possa subsidiar a análise sobre a dimensão gestão escolar. Foram consultadas as bases de dados SciELO e Pepsic, e selecionadas obras que abordassem a evolução do conceito de gestão escolar no Brasil e no mundo. Na base de dados não houve preocupação com a classificação pelo Qualis dos periódicos. 
Analisaram-se artigos e teses de 2005 até 2015, utilizando-se as bases de dados da literatura brasileira do SciELO e de produções internacionais do portal de periódicos Capes. Optou-se por não realizar o levantamento de dissertações, apenas de teses e artigos científicos. Para as teses, utilizou-se a base de dados do Instituto Brasileiro de Informação em Ciência e Tecnologia - Ibict - banco de teses e dissertações. Para as categorias de análise, as palavras-chave foram: gestão escolar, gestão democrática, administração escolar e diretor/gestor de escola. Observou-se que, ao fazer a articulação das palavras-chave, muitas publicações apareciam repetidas.

Foram identificadas a princípio 187 produções. Após a leitura, percebeu-se que algumas publicações não preenchiam os critérios deste estudo, fugindo do tema gestão escolar ou trazendo uma abrangência que não representava o objeto de estudo da pesquisa; foram, portanto, descartadas. Todas foram lidas na íntegra e foram realizados fichamentos com o objetivo de organizar e analisar conceitos, métodos e abordagens teóricas. Após o uso desse critério de escolha, foram selecionados 86 artigos, sendo 56 nacionais e 31 internacionais e 15 teses, das quais 13 são nacionais e duas são internacionais, num total de 101 produções que seguem abaixo em dois quadros. O primeiro traz as teses analisadas, e o segundo, os artigos científicos.

\section{QUADRO 1}

TESES SOBRE GESTÃO ESCOLAR

\begin{tabular}{|c|c|c|c|}
\hline AUTOR & TÍTULO & ANO & IES \\
\hline $\begin{array}{l}\text { BARATA, Margarida Maria } \\
\text { Soares de Carvalho }\end{array}$ & $\begin{array}{l}\text { Gestão e administração escolar: do modelo liceal à } \\
\text { actualidade }\end{array}$ & 2007 & $\begin{array}{l}\text { Universidade } \\
\text { Portucalense }\end{array}$ \\
\hline BARBOSA, Andrea Haddad & $\begin{array}{l}\text { O tempo e o espaço da administração educacional na } \\
\text { formação do pedagogo: um mapeamento a partir dos } \\
\text { projetos político-pedagógicos de universidades públicas }\end{array}$ & 2014 & Unesp ${ }^{1}$ \\
\hline CARNEIRO, Tulio Andrade & $\begin{array}{l}\text { Financiamento, gestão e qualidade da educação escolar } \\
\text { pública: um estudo de caso em escolas públicas da } \\
\text { cidade do Recife }\end{array}$ & 2012 & UFPE ${ }^{2}$ \\
\hline FERNANDEZ, Silvina Julia & $\begin{array}{l}\text { Gestão escolar e cidadania: um estudo de caso através } \\
\text { de memórias, diálogos e encruzilhadas nas relações } \\
\text { mães-escola }\end{array}$ & 2011 & $\mathrm{UFF}^{3}$ \\
\hline
\end{tabular}


(Continuação)

\begin{tabular}{|c|c|c|c|}
\hline AUTOR & TÍTULO & ANO & IES \\
\hline $\begin{array}{l}\text { HESSEL, Ana Maria Di } \\
\text { Grado }\end{array}$ & $\begin{array}{l}\text { Formação online de gestores escolares: atitude } \\
\text { interdisciplinar nas narrativas dos diários de bordo }\end{array}$ & 2009 & PUC-SP 4 \\
\hline LEITE, Fernando Valente & A gestão como factor de sucesso escolar & 2005 & $\begin{array}{l}\text { Universidade de } \\
\text { Aveiro }\end{array}$ \\
\hline LIMA, Erivelton Silva & O diretor e as avaliações praticadas na escola & 2011 & $\mathrm{UnB}^{5}$ \\
\hline LOPES, Antonio. & $\begin{array}{l}\text { Gestão escolar e parcerias em educação no município de } \\
\text { Votuporanga }\end{array}$ & 2006 & Unesp \\
\hline MILITÃO, Andréia Nunes & $\begin{array}{l}\text { A complexidade da administração/gestão escolar: limites } \\
\text { e possibilidades }\end{array}$ & 2015 & Unesp \\
\hline ROSA, José Paulo da & $\begin{array}{l}\text { Gestão escolar: um modelo para a qualidade Brasil e } \\
\text { Coreia }\end{array}$ & 2011 & $P \cup C-R S^{6}$ \\
\hline $\begin{array}{l}\text { SALOMAO, Maria Silvia } \\
\text { Azarite. }\end{array}$ & $\begin{array}{l}\text { Impacto de programas de formação continuada da } \\
\text { Secretaria Estadual de Educação de São Paulo na gestão } \\
\text { escolar }\end{array}$ & 2011 & Unesp \\
\hline SCHENECKENBERG, M. & $\begin{array}{l}\text { O princípio democrático na atuação do diretor da escola: } \\
\text { um estudo comparativo entre diretores eleitos e reeleitos } \\
\text { da Rede Pública Municipal de Ensino de Ponta Grossa }\end{array}$ & 2005 & Unicamp ${ }^{7}$ \\
\hline SILVA, Nilson Robson G. & $\begin{array}{l}\text { Gestão escolar democrática: uma contextualização do } \\
\text { tema }\end{array}$ & 2009 & UFC ${ }^{8}$ \\
\hline SOUZA, Angelo Ricardo de & Perfil da gestão escolar no Brasil & 2007 & PUC-SP \\
\hline TOME, Marta Fresneda & $\begin{array}{l}\text { A educação infantil foi para a escola, e agora? Ensaio } \\
\text { de uma teoria para a gestão institucional da educação } \\
\text { infantil }\end{array}$ & 2011 & UEP \\
\hline
\end{tabular}

Fonte: Elaboração das autoras. 
QUADRO 2

ARTIGOS SOBRE GESTÃO ESCOLAR

\begin{tabular}{|c|c|c|c|}
\hline AUTOR & TÍTULO & ANO & REVISTA \\
\hline ABRANTES, Pedro & $\begin{array}{l}\text { Políticas de avaliação e avaliação de } \\
\text { políticas: o caso português no contexto } \\
\text { ibero-americano }\end{array}$ & 2010 & $\begin{array}{l}\text { Revista } \\
\text { Iberoamericana } \\
\text { de Educación }\end{array}$ \\
\hline $\begin{array}{l}\text { ABDIAN, Graziela Zambão; HOJAS, } \\
\text { Viviani Fernanda; OLIVEIRA, Maria Eliza } \\
\text { Nogueira }\end{array}$ & $\begin{array}{l}\text { Formação e função e formas de provimento } \\
\text { do cargo do gestor escolar: as diretrizes da } \\
\text { política educacional e o desenvolvimento } \\
\text { teórico da administração escolar }\end{array}$ & 2012 & $\begin{array}{l}\text { Educação } \\
\text { Temática } \\
\text { Digital }\end{array}$ \\
\hline $\begin{array}{l}\text { ABDIAN, Graziela Zambão; HOJAS, } \\
\text { Viviani Fernanda; OLIVEIRA, Maria Eliza } \\
\text { Nogueira }\end{array}$ & $\begin{array}{l}\text { Função do diretor na escola pública } \\
\text { paulista: mudanças e permanências }\end{array}$ & 2013 & $\begin{array}{l}\text { Educação e } \\
\text { Realidade }\end{array}$ \\
\hline AGUIAR, Márcia Angela da S. & $\begin{array}{l}\text { Gestão da educação básica e o } \\
\text { fortalecimento dos conselhos escolares }\end{array}$ & 2008 & Educar \\
\hline AGUILAR Hernández, Luis & $\begin{array}{l}\text { Políticas del cambio en educación y gestión } \\
\text { de la innovación }\end{array}$ & 2009 & Innovar \\
\hline $\begin{array}{l}\text { ALMEIDA, Andreia Pereira de; } \\
\text { JUNQUILHO, Gelson Silva; SOUZA, } \\
\text { Susane Petinelli }\end{array}$ & $\begin{array}{l}\text { Programa Escola Campeã na Gestão } \\
\text { Escolar: o hibridismo entre a racionalidade } \\
\text { burocrática e uma "anarquia organizada" }\end{array}$ & 2008 & $\begin{array}{l}\text { Gestão e } \\
\text { Tecnologia }\end{array}$ \\
\hline ANDERSON, Stephen & $\begin{array}{l}\text { The shool district's role in educational } \\
\text { change }\end{array}$ & 2006 & $\begin{array}{l}\text { International } \\
\text { Journal of Ed. } \\
\text { Reform }\end{array}$ \\
\hline AFONSO, Almerindo Janela & $\begin{array}{l}\text { Nem tudo o que conta em educação } \\
\text { é mensurável ou comparável: crítica } \\
\text { à accountability baseada em testes } \\
\text { estandardizados e rankings escolares }\end{array}$ & 2009 & $\begin{array}{l}\text { Revista } \\
\text { Lusófona de } \\
\text { Educação }\end{array}$ \\
\hline ALVES, Mariana Gaio; VARELA, Teresa & $\begin{array}{l}\text { Construir a relação escola-comunidade } \\
\text { educativa: uma abordagem exploratória no } \\
\text { concelho de Almada }\end{array}$ & 2012 & $\begin{array}{l}\text { Revista } \\
\text { Portuguesa de } \\
\text { Educação }\end{array}$ \\
\hline ALVES, Wanderson Ferreira & $\begin{array}{l}\text { Gestão escolar e o trabalho dos educadores: } \\
\text { da estreiteza das políticas à complexidade } \\
\text { do trabalho humano }\end{array}$ & 2010 & $\begin{array}{l}\text { Educação e } \\
\text { Sociedade }\end{array}$ \\
\hline ASLLANARGUN, Engin & $\begin{array}{l}\text { Educacional principals' values in school } \\
\text { administration }\end{array}$ & 2012 & $\begin{array}{l}\text { Educational } \\
\text { Sciences: } \\
\text { theory \& } \\
\text { practice }\end{array}$ \\
\hline BARBOSA, Joaquim Gonçalves & $\begin{array}{l}\text { Administração educacional } \\
\text { multirreferencial: uma aprendizagem em } \\
\text { sala de aula }\end{array}$ & 2005 & $\begin{array}{l}\text { Educação } \\
\text { Marista }\end{array}$ \\
\hline BARROSO, João & $\begin{array}{l}\text { A utilização do conhecimento em política: o } \\
\text { caso da gestão escolar em Portugal }\end{array}$ & 2009 & $\begin{array}{l}\text { Educação e } \\
\text { Sociedade }\end{array}$ \\
\hline BASS, Bernard; BASS, Ruth & $\begin{array}{l}\text { The Bass Handbook of Leadership: theory, } \\
\text { research \& managerial applications }\end{array}$ & 2008 & Free Press NY \\
\hline $\begin{array}{l}\text { BERALDO, Fernando; PELOZO, Rita de } \\
\text { Cássia Borguetti }\end{array}$ & $\begin{array}{l}\text { A gestão participativa na escola: tendências } \\
\text { e perspectivas }\end{array}$ & 2007 & $\begin{array}{l}\text { Revista } \\
\text { Científica } \\
\text { Eletrônica } \\
\text { Pedagógica }\end{array}$ \\
\hline BLASI, Jacqueline de; FALCÃO, Sandra P. & Gestão participativa na escola & 2008 & Sinergia \\
\hline BRICEÑO, Mario Uribe & $\begin{array}{l}\text { Profesionalizar la dirección escolar } \\
\text { potenciando el liderazgo: una clave } \\
\text { ineludible en la mejora escolar. Desarrollo } \\
\text { de perfiles de competências directivas en el } \\
\text { sistema educativo chileno }\end{array}$ & 2010 & $\begin{array}{l}\text { Revista } \\
\text { Iberoamericana } \\
\text { de Evaluación } \\
\text { Educativa }\end{array}$ \\
\hline BORTOLINI, Jairo Cézar & $\begin{array}{l}\text { O papel do diretor na gestão democrática: } \\
\text { desafios e possibilidades na prática da } \\
\text { gestão escolar }\end{array}$ & 2013 & Interletras \\
\hline
\end{tabular}

(Continua) 
(Continuação)

\begin{tabular}{|c|c|c|c|}
\hline AUTOR & TÍTULO & ANO & REVISTA \\
\hline CARVALHO, Maria João de & $\begin{array}{l}\text { A modalidade de escolha do diretor na } \\
\text { escola pública portuguesa }\end{array}$ & 2012 & $\begin{array}{l}\text { Revista } \\
\text { Lusófona de } \\
\text { Educação }\end{array}$ \\
\hline CATTONAR, Branka & $\begin{array}{l}\text { Evolução do modo de regulação escolar } \\
\text { e reestruturação da função de diretor de } \\
\text { escola }\end{array}$ & 2006 & $\begin{array}{l}\text { Educação em } \\
\text { Revista }\end{array}$ \\
\hline CASTRO, Magali de & $\begin{array}{l}\text { A formação de professores e gestores para } \\
\text { os anos iniciais da educação básica: das } \\
\text { origens às diretrizes curriculares nacionais }\end{array}$ & 2007 & $\begin{array}{l}\text { Revista } \\
\text { Brasileira } \\
\text { de Política e } \\
\text { Administração } \\
\text { da Educação }\end{array}$ \\
\hline CORREIA, José Alberto & $\begin{array}{l}\text { Paradigmas e cognição no campo de } \\
\text { administração escolar: das políticas de } \\
\text { avaliação à avaliação como política }\end{array}$ & 2010 & $\begin{array}{l}\text { Revista } \\
\text { Brasileira de } \\
\text { Educação }\end{array}$ \\
\hline $\begin{array}{l}\text { DI GIORGI, Cristiano Amaral G.; LEITE, } \\
\text { Yoshie Ussami Ferrari }\end{array}$ & $\begin{array}{l}\text { A qualidade da escola pública, na } \\
\text { perspectiva democrática e popular }\end{array}$ & 2010 & $\begin{array}{l}\text { Série-Estudos. } \\
\text { Periódico do } \\
\text { Mestrado em } \\
\text { Educação da } \\
\text { UCDB }\end{array}$ \\
\hline $\begin{array}{l}\text { DONOSO, Sebastián; BENAVIDES, } \\
\text { Nibaldo; CANCINO, Víctor; CASTRO, } \\
\text { Moyra; LÓPEZ, Leopoldo }\end{array}$ & $\begin{array}{l}\text { Análisis crítico de las políticas de formación } \\
\text { de directivos escolares en Chile: 1980-2010. }\end{array}$ & 2012 & $\begin{array}{l}\text { Revista } \\
\text { Brasileira de } \\
\text { Educação }\end{array}$ \\
\hline DONOSO, Sebastian & $\begin{array}{l}\text { El financiamiento de la educación pública } \\
\text { chilena vía subsidio: consecuencias críticas } \\
\text { sobre el rol del estado en educación }\end{array}$ & 2011 & $\begin{array}{l}\text { Revista de } \\
\text { Financiamento } \\
\text { da Educação }\end{array}$ \\
\hline DONOSO, Sebastian & $\begin{array}{l}\text { El perfeccionamiento docente en Chile } \\
\text { (1990-2007): ¿Estado versus mercado? }\end{array}$ & 2008 & $\begin{array}{l}\text { Revista } \\
\text { Brasileira de } \\
\text { Educação }\end{array}$ \\
\hline DORA, Rosemary & $\begin{array}{l}\text { Gramsci e o debate sobre a escola pública } \\
\text { no Brasil }\end{array}$ & 2006 & $\begin{array}{l}\text { Cadernos } \\
\text { CEDES }\end{array}$ \\
\hline DOURADO, Luiz Fernandes & $\begin{array}{l}\text { Políticas e gestão da educação básica no } \\
\text { Brasil: limites e perspectivas }\end{array}$ & 2007 & $\begin{array}{l}\text { Educação e } \\
\text { Sociedade }\end{array}$ \\
\hline $\begin{array}{l}\text { DOURADO, Luiz Fernandes; OLIVEIRA, } \\
\text { João Ferreira de }\end{array}$ & $\begin{array}{l}\text { A qualidade da educação: perspectivas e } \\
\text { desafios }\end{array}$ & 2009 & $\begin{array}{l}\text { Cadernos } \\
\text { CEDES }\end{array}$ \\
\hline $\begin{array}{l}\text { DRABACH, Neila Pedrotti; MOUSQUER, } \\
\text { Maria Elizabete Londero }\end{array}$ & $\begin{array}{l}\text { Dos primeiros escritos sobre administração } \\
\text { escolar no Brasil aos escritos sobre gestão } \\
\text { escolar }\end{array}$ & 2009 & $\begin{array}{l}\text { Currículo sem } \\
\text { Fronteiras }\end{array}$ \\
\hline $\begin{array}{l}\text { FERNANDES, Maria Elizabeth; MULLER, } \\
\text { Antônio José }\end{array}$ & Função do gestor na escola pública & 2006 & $\begin{array}{l}\text { Revista de } \\
\text { Divulgação } \\
\text { Científica ICPG }\end{array}$ \\
\hline $\begin{array}{l}\text { FERREIRA, Simone Marques; } \\
\text { MARIOTINI, Sergio Donizeti }\end{array}$ & $\begin{array}{l}\text { O papel do diretor de escola: contrapontos } \\
\text { da administração e da gestão escolar }\end{array}$ & 2015 & $\begin{array}{l}\text { Ensino e } \\
\text { Sociedade }\end{array}$ \\
\hline FULLAN, Michael & The role of the district in TRI level reform & 2010 & $\begin{array}{l}\text { International } \\
\text { Encyclopedia } \\
\text { of Education }\end{array}$ \\
\hline $\begin{array}{l}\text { GALVAO, Veronica Bezerra de } \\
\text { Araújo; SILVA, Anielson Barbosa da; } \\
\text { SILVA, Walmir Rufino da }\end{array}$ & $\begin{array}{l}\text { O desenvolvimento de competências } \\
\text { gerenciais nas escolas públicas estaduais }\end{array}$ & 2011 & $\begin{array}{l}\text { Educação e } \\
\text { Pesquisa }\end{array}$ \\
\hline GOMES, Candido Alberto & $\begin{array}{l}\text { A escola de qualidade para todos: abrindo } \\
\text { as camadas da cebola }\end{array}$ & 2005 & $\begin{array}{l}\text { Revista de } \\
\text { Administração } \\
\text { Pública }\end{array}$ \\
\hline $\begin{array}{l}\text { GOMES, Alfredo Macedo; SANTOS, Ana } \\
\text { Lúcia Félix dos; MELO, Darci Barbosa } \\
\text { Lira de }\end{array}$ & $\begin{array}{l}\text { Escola de gestores: política de formação em } \\
\text { gestão escolar }\end{array}$ & 2009 & $\begin{array}{l}\text { Revista } \\
\text { Brasileira } \\
\text { de Política e } \\
\text { Administração } \\
\text { da Educação }\end{array}$ \\
\hline
\end{tabular}


(Continuação)

\begin{tabular}{|c|c|c|c|}
\hline AUTOR & TÍTULO & ANO & REVISTA \\
\hline $\begin{array}{l}\text { HACKMANN, Donald; ALSBUURY, } \\
\text { Thomas }\end{array}$ & $\begin{array}{l}\text { Standards-based leadership preparation } \\
\text { improvement through the use of portfolio } \\
\text { assessments }\end{array}$ & 2015 & $\begin{array}{l}\text { Educational } \\
\text { Considerations }\end{array}$ \\
\hline HSIEH, Chung; URQUIOLA, Miquel & $\begin{array}{l}\text { The effects of generalized school choice on } \\
\text { achievement and stratification: evidence } \\
\text { from Chile's voucher program }\end{array}$ & 2006 & $\begin{array}{l}\text { Journal } \\
\text { of Public } \\
\text { Economics }\end{array}$ \\
\hline $\begin{array}{l}\text { JUNQUILHO, Gelson Silva; ALMEIDA, } \\
\text { Roberta Alvarenga de; SILVA, Alfredo } \\
\text { Rodrigues Leite da }\end{array}$ & $\begin{array}{l}\text { As "artes do fazer" gestão na escola pública: } \\
\text { uma proposta de estudo }\end{array}$ & 2012 & $\begin{array}{l}\text { Cadernos } \\
\text { EBAPE }\end{array}$ \\
\hline LIMA, Licínio Carlos Viana da Silva & $\begin{array}{l}\text { O agrupamento de escolas como novo } \\
\text { escalão da administração desconcentrada }\end{array}$ & 2005 & $\begin{array}{l}\text { Revista } \\
\text { Portuguesa de } \\
\text { Educação }\end{array}$ \\
\hline LIMA, Licínio Carlos Viana da Silva & $\begin{array}{l}\text { A gestão democrática das escolas: do } \\
\text { autogoverno à ascensão de uma pós- } \\
\text { democracia gestionária? }\end{array}$ & 2014 & $\begin{array}{l}\text { Educação e } \\
\text { Sociedade }\end{array}$ \\
\hline $\begin{array}{l}\text { LUPORINI, Teresa J.; MARTINIAK, Vera } \\
\text { Lúcia; MAROCHI, Zélia Maria L. }\end{array}$ & $\begin{array}{l}\text { Eleição e formação de diretores de escolas } \\
\text { municipais: a legislação e as práticas da } \\
\text { rede municipal de ensino de Ponta Grossa }\end{array}$ & 2011 & $\begin{array}{l}\text { Revista } \\
\text { HISTEDBR }\end{array}$ \\
\hline $\begin{array}{l}\text { MAIA, Graziela Zambão Abdian; } \\
\text { MACHADO, Lourdes Marcelino }\end{array}$ & $\begin{array}{l}\text { As publicações da ANPAE e a trajetória } \\
\text { do conhecimento em administração da } \\
\text { educação no Brasil }\end{array}$ & 2008 & $\begin{array}{l}\text { Revista } \\
\text { Brasileira } \\
\text { de Política e } \\
\text { Administração } \\
\text { da Educação }\end{array}$ \\
\hline MAINARDES Jefferson & $\begin{array}{l}\text { Abordagem do Ciclo de Políticas: uma } \\
\text { contribuição para a análise de políticas } \\
\text { educacionais }\end{array}$ & 2006 & $\begin{array}{l}\text { Educação e } \\
\text { Sociedade }\end{array}$ \\
\hline MARQUES, Luciana Rosa & $\begin{array}{l}\text { Caminhos da democracia nas políticas de } \\
\text { descentralização da gestão escolar }\end{array}$ & 2006 & $\begin{array}{l}\text { Ensaio: } \\
\text { Avaliação } \\
\text { e Políticas } \\
\text { Públicas em } \\
\text { Educação }\end{array}$ \\
\hline MARQUES, Luciana Rosa & $\begin{array}{l}\text { A formação de uma cultura democrática } \\
\text { na gestão da escola pública: analisando o } \\
\text { discurso dos conselheiros escolares }\end{array}$ & 2012 & $\begin{array}{l}\text { Educação e } \\
\text { Sociedade }\end{array}$ \\
\hline MARQUES, Waldemar & $\begin{array}{l}\text { Administração escolar: uma perspectiva } \\
\text { crítica para a atualidade }\end{array}$ & 2012 & $\begin{array}{l}\text { Série-Estudos } \\
\text { Periódico do } \\
\text { Mestrado em } \\
\text { Educação da } \\
\text { UCDB }\end{array}$ \\
\hline MARTINS, Angela Maria & $\begin{array}{l}\text { Gestão e autonomia escolar: um estudo } \\
\text { comparado Brasil/Portugal }\end{array}$ & 2011 & $\begin{array}{l}\text { Revista } \\
\text { Brasileira de } \\
\text { Educação }\end{array}$ \\
\hline $\begin{array}{l}\text { MARTINS, Angela Maria; SILVA, Vandré } \\
\text { Gomes da }\end{array}$ & $\begin{array}{l}\text { Estado da arte: gestão, autonomia da escola } \\
\text { e órgãos colegiados }\end{array}$ & 2011 & $\begin{array}{l}\text { Cadernos de } \\
\text { Pesquisa }\end{array}$ \\
\hline MARTINS, Angela Maria & $\begin{array}{l}\text { Aspectos organizacionais e dinâmicos na } \\
\text { gestão da escola pública: dilemas e conflitos }\end{array}$ & 2008 & $\begin{array}{l}\text { Revista } \\
\text { Brasileira } \\
\text { de Política e } \\
\text { Administração } \\
\text { da Educação }\end{array}$ \\
\hline MARTINS, Angela Maria & $\begin{array}{l}\text { O contexto escolar e a dinâmica de órgãos } \\
\text { colegiados: uma contribuição ao debate } \\
\text { sobre gestão de escolas }\end{array}$ & 2008 & $\begin{array}{l}\text { Revista Ensaio: } \\
\text { APBE }\end{array}$ \\
\hline $\begin{array}{l}\text { MOHD ALI, Hairuddin; YANGAIYA, } \\
\text { Salisu Abba }\end{array}$ & $\begin{array}{l}\text { Investigating the influence of distributed } \\
\text { leadership on school effectiveness: a } \\
\text { mediating role of teachers' commitment }\end{array}$ & 2015 & $\begin{array}{l}\text { Journal of } \\
\text { Educational } \\
\text { and Social } \\
\text { Research }\end{array}$ \\
\hline
\end{tabular}


(Continuação)

\begin{tabular}{|c|c|c|c|}
\hline AUTOR & TíTULO & ANO & REVISTA \\
\hline TORRECILLA, Francisco Javier Murillo & $\begin{array}{l}\text { Una dirección escolar para el cambio: del } \\
\text { liderazgo transformacional al liderazgo } \\
\text { distribuido }\end{array}$ & 2006 & $\begin{array}{l}\text { Revista } \\
\text { Eletrônica } \\
\text { Iberoamericana }\end{array}$ \\
\hline NÓVOA, António & Educação 2021: Para uma história do futuro & 2009 & $\begin{array}{l}\text { Revista } \\
\text { Eletrônica } \\
\text { Iberoamericana }\end{array}$ \\
\hline $\begin{array}{l}\text { OLIVEIRA, Eny da Luz Lacerda; } \\
\text { ALENCAR, Eunice Maria Lima Soriano } \\
\text { de }\end{array}$ & $\begin{array}{l}\text { Criatividade e escola: limites e } \\
\text { possibilidades segundo gestores e } \\
\text { orientadores educacionais }\end{array}$ & 2010 & $\begin{array}{l}\text { Revista } \\
\text { Semestral da } \\
\text { Associação } \\
\text { Brasileira de } \\
\text { Psicologia } \\
\text { Escolar e } \\
\text { Educacional }\end{array}$ \\
\hline OZGA, Jenny & $\begin{array}{l}\text { Governing education through data in } \\
\text { England: from regulation to self-evaluation }\end{array}$ & 2009 & $\begin{array}{l}\text { Journal of } \\
\text { Education } \\
\text { Policy }\end{array}$ \\
\hline PARO, Vitor & $\begin{array}{l}\text { A educação, a política e a administração: } \\
\text { reflexões sobre a prática do diretor de } \\
\text { escola }\end{array}$ & 2010 & $\begin{array}{l}\text { Educação e } \\
\text { Pesquisa }\end{array}$ \\
\hline PARO, Vitor & $\begin{array}{l}\text { Formação de gestores escolares: a } \\
\text { atualidade de José Quirino Ribeiro }\end{array}$ & 2009 & $\begin{array}{l}\text { Educação e } \\
\text { Sociedade }\end{array}$ \\
\hline $\begin{array}{l}\text { PENTEADO, Thaís Carvalho Zanchetta; } \\
\text { GUZZO, Raquel Souza Lobo }\end{array}$ & $\begin{array}{l}\text { Educação e psicologia: a construção de um } \\
\text { projeto político-pedagógico emancipador }\end{array}$ & 2010 & $\begin{array}{l}\text { Psicologia e } \\
\text { Sociedade }\end{array}$ \\
\hline PERRYMAN, Jane & $\begin{array}{l}\text { Panoptic performativity and school } \\
\text { inspection regimes: disciplinary mechanisms } \\
\text { and life under special measures }\end{array}$ & 2006 & $\begin{array}{l}\text { Journal of } \\
\text { Education } \\
\text { Policy }\end{array}$ \\
\hline PERRYMAN, Jane & $\begin{array}{l}\text { Inspection and the fabrication of } \\
\text { professional and performative processes }\end{array}$ & 2009 & $\begin{array}{l}\text { Journal of } \\
\text { Education } \\
\text { Policy }\end{array}$ \\
\hline REITER, Bernd & $\begin{array}{l}\text { Education reform, race, and politics in } \\
\text { Bahia, Brazil }\end{array}$ & 2008 & $\begin{array}{l}\text { Revista Ensaio: } \\
\text { APBE }\end{array}$ \\
\hline $\begin{array}{l}\text { RINGLER, Marjorie; ROUSE, William; ST. } \\
\text { CLAIR, Randy }\end{array}$ & $\begin{array}{l}\text { Evaluation masters of scholl administration } \\
\text { internship experiences: practices and } \\
\text { competencies quantified }\end{array}$ & 2012 & $\begin{array}{l}\text { NCPEA } \\
\text { Publications }\end{array}$ \\
\hline ROCKWELL, Elsie; EZPELETA, Justa & $\begin{array}{l}\text { A escola: relato de um processo inacabado } \\
\text { de construção }\end{array}$ & 2007 & $\begin{array}{l}\text { Currículo sem } \\
\text { Fronteiras }\end{array}$ \\
\hline SANDER, Benno & $\begin{array}{l}\text { A pesquisa sobre políticas e gestão da } \\
\text { educação no Brasil: uma leitura introdutória } \\
\text { sobre sua construção }\end{array}$ & 2007 & $\begin{array}{l}\text { Revista } \\
\text { Brasileira } \\
\text { de Política e } \\
\text { Administração } \\
\text { da Educação }\end{array}$ \\
\hline $\begin{array}{l}\text { SANTOS, Márcio José dos; PAULA, } \\
\text { Claudio Paixão Anastácio de }\end{array}$ & $\begin{array}{l}\text { Gestão do conhecimento no contexto da } \\
\text { gestão escolar: estudo de caso de uma } \\
\text { escola pública }\end{array}$ & 2012 & $\begin{array}{l}\text { Perspectiva } \\
\text { em Gestão \& } \\
\text { Conhecimento }\end{array}$ \\
\hline SILVA, Eliene Pereira da & $\begin{array}{l}\text { A importância do gestor educacional na } \\
\text { instituição }\end{array}$ & 2009 & $\begin{array}{l}\text { Revista } \\
\text { Conteúdo }\end{array}$ \\
\hline SOARES, Tuffi Machado et al. & A gestão escolar e o IDEB da escola & 2011 & $\begin{array}{l}\text { Pesquisa e } \\
\text { Debate em } \\
\text { Educação }\end{array}$ \\
\hline SOUZA, Angelo Ricardo de & $\begin{array}{l}\text { A produção do conhecimento e o ensino da } \\
\text { gestão educacional no Brasil }\end{array}$ & 2008 & $\begin{array}{l}\text { Revista } \\
\text { Brasileira } \\
\text { de Política e } \\
\text { Administração } \\
\text { da Educação }\end{array}$ \\
\hline
\end{tabular}

(Continua) 
(Continuação)

\begin{tabular}{|c|c|c|c|}
\hline AUTOR & TíTULO & ANO & REVISTA \\
\hline SOUZA, Angelo Ricardo de & $\begin{array}{l}\text { A pesquisa no campo da gestão da } \\
\text { educação: algumas reflexões sobre as } \\
\text { relações entre produção do conhecimento e } \\
\text { a prática da gestão educacional }\end{array}$ & 2009 & $\begin{array}{l}\text { Retratos da } \\
\text { Escola }\end{array}$ \\
\hline SOUZA, Angelo Ricardo de & $\begin{array}{l}\text { Perfil da gestão da escola pública no Brasil: } \\
\text { um estudo sobre os diretores escolares e } \\
\text { sobre aspectos da gestão democrática }\end{array}$ & 2009 & $\begin{array}{l}\text { Revista } \\
\text { Iberoamericana } \\
\text { de Educación }\end{array}$ \\
\hline SoUZA, Ângelo Ricardo de & $\begin{array}{l}\text { Explorando e construindo um conceito de } \\
\text { gestão escolar democrática }\end{array}$ & 2009 & $\begin{array}{l}\text { Educação em } \\
\text { Revista }\end{array}$ \\
\hline SOUZA, Ângelo Ricardo de & $\begin{array}{l}\text { A natureza política da gestão escolar e as } \\
\text { disputas pelo poder na escola }\end{array}$ & 2012 & $\begin{array}{l}\text { Revista } \\
\text { Brasileira de } \\
\text { Educação }\end{array}$ \\
\hline $\begin{array}{l}\text { SOUZA, Ângelo Ricardo de; GOUVEIA, } \\
\text { Andréa Barbosa }\end{array}$ & $\begin{array}{l}\text { Diretores de escolas públicas: aspectos do } \\
\text { trabalho docente }\end{array}$ & 2010 & $\begin{array}{l}\text { Educação em } \\
\text { Revista }\end{array}$ \\
\hline SOUZA, Angelo Ricardo de & $\begin{array}{l}\text { Os caminhos da produção científica sobre a } \\
\text { gestão escolar no Brasil }\end{array}$ & 2006 & $\begin{array}{l}\text { Revista } \\
\text { Brasileira } \\
\text { de Política e } \\
\text { Administração }\end{array}$ \\
\hline SOUZA, Genival Nunes & $\begin{array}{l}\text { Gestão democrática escolar: reflexões e } \\
\text { desafios }\end{array}$ & 2011 & $\begin{array}{l}\text { Revista } \\
\text { Dialógica }\end{array}$ \\
\hline $\begin{array}{l}\text { SOUZA, Ângelo Ricardo de; TEIXEIRA, } \\
\text { Maria Aparecida Pereira }\end{array}$ & $\begin{array}{l}\text { O Programa Escola de Gestores: análise da } \\
\text { experiência no estado do Paraná }\end{array}$ & 2010 & $\begin{array}{l}\text { Educare } \\
\text { Educere }\end{array}$ \\
\hline TORRES, Carlos Alberto & $\begin{array}{l}\text { Struggling for the soul of the nation. } \\
\text { Educational policy, democratic leadership, } \\
\text { and radical democracy in neoliberal times }\end{array}$ & 2011 & $\begin{array}{l}\text { Scholar- } \\
\text { Practitioner } \\
\text { Quarterly }\end{array}$ \\
\hline $\begin{array}{l}\text { TORRES, Leonor Lima; PALHARES, } \\
\text { José A. }\end{array}$ & Estilos de liderança e escola democrática & 2009 & $\begin{array}{l}\text { Revista } \\
\text { Lusófona de } \\
\text { Educação }\end{array}$ \\
\hline $\begin{array}{l}\text { TORRES, Leonor Lima; PALHARES, } \\
\text { José A. }\end{array}$ & $\begin{array}{l}\text { Liderança singular na escola plural: as } \\
\text { culturas da escola perante o processo de } \\
\text { avaliação externa }\end{array}$ & 2013 & $\begin{array}{l}\text { Revista } \\
\text { Lusófona de } \\
\text { Educação }\end{array}$ \\
\hline TORRES, Leonor Lima & $\begin{array}{l}\text { A construção da autonomia num } \\
\text { contexto de dependências: limitações e } \\
\text { possibilidades nos processos de (in)decisão } \\
\text { na escola pública }\end{array}$ & 2011 & $\begin{array}{l}\text { Educação, } \\
\text { Sociedade \& } \\
\text { Culturas }\end{array}$ \\
\hline TORRES, Leonor Lima & $\begin{array}{l}\text { A escola como entreposto cultural: o } \\
\text { cultural e o simbólico no desenvolvimento } \\
\text { democrático da escola }\end{array}$ & 2008 & $\begin{array}{l}\text { Revista } \\
\text { Portuguesa de } \\
\text { Educação }\end{array}$ \\
\hline $\begin{array}{l}\text { TRIGO, João Ribeiro; COSTA, Jorge } \\
\text { Adelino }\end{array}$ & $\begin{array}{l}\text { Liderança nas organizações educativas: a } \\
\text { direção por valores }\end{array}$ & 2008 & $\begin{array}{l}\text { Ensaio: } \\
\text { Avaliação, } \\
\text { e Políticas } \\
\text { Públicas em } \\
\text { Educação }\end{array}$ \\
\hline $\begin{array}{l}\text { VARGAS, Roberta Alvarenga de } \\
\text { Almeida; JUNQUILHO, Gelson Silva }\end{array}$ & $\begin{array}{l}\text { Funções administrativas ou práticas? As } \\
\text { "artes do fazer" gestão na Escola Mirante }\end{array}$ & 2013 & $\begin{array}{l}\text { Revista } \\
\text { Ciências da } \\
\text { Administração }\end{array}$ \\
\hline $\begin{array}{l}\text { VELOSO, Luísa; ABRANTES, Pedro; } \\
\text { CRAVEIRO, Daniela }\end{array}$ & $\begin{array}{l}\text { A avaliação externa de escolas como } \\
\text { processo social }\end{array}$ & 2011 & $\begin{array}{l}\text { Educação, } \\
\text { Sociedade \& } \\
\text { Culturas }\end{array}$ \\
\hline $\begin{array}{l}\text { WEINSTEIN, José; MUÑOZ, Gonzalo; } \\
\text { HORN, Andrea; MARFÁN, Javiera }\end{array}$ & $\begin{array}{l}\text { Prácticas de liderazgo directivo y resultados } \\
\text { de aprendizaje. Hacia conceptos capaces de } \\
\text { guiar la investigación empírica }\end{array}$ & 2009 & $\begin{array}{l}\text { Revista } \\
\text { Iberoam. } \\
\text { Calydade. Ef. } \\
\text { Cambio Educ. }\end{array}$ \\
\hline YOLCU, Hüseyin & $\begin{array}{l}\text { Decentralization of education and } \\
\text { strengthening the participation of parents } \\
\text { in school administration in Turkey: what has } \\
\text { changed? }\end{array}$ & 2011 & $\begin{array}{l}\text { Educational } \\
\text { Sciences: } \\
\text { Theory e } \\
\text { Practice }\end{array}$ \\
\hline
\end{tabular}

Fonte: Elaboração das autoras. 
Após a leitura, as publicações foram organizadas pelos seguintes critérios: quantidade, ano e tipo de produção; conceito de gestão escolar apresentado (ou não); e a abordagem teórica empregada. Em seguida, realizou-se o estudo qualitativo dos dados, através da análise de conteúdo. Bardin (2011) aponta que a análise de conteúdo permite uma maior compreensão através de categorias. Trata-se, segundo a autora, da realização de uma apreciação temática na qual se observam os "núcleos de sentido" que compõem aquela comunicação. Foram geradas categorias a partir da leitura e da avaliação do material selecionado, as quais permitiram observar semelhanças e distinções entre os trabalhos.

Observou-se que, no campo educacional, um mesmo objeto de estudo pode ser nomeado por diversos termos, tais como "gestão" e "administração" escolar. Também se percebeu o contrário: que termos considerados como sinônimos por alguns autores apresentam-se conceituados de forma diferenciada por outros, como "gestão democrática" e "gestão participativa". Para facilitar a categorização, buscou-se considerar não apenas o objeto explícito das pesquisas, mas também terminologias utilizadas pelos pesquisadores que indicavam a semelhança entre os termos utilizados. As unidades de registro passaram por sucessivos agrupamentos até que se chegasse às categorias finais, de forma a dar mais clareza ao conteúdo abordado. As categorias finais abrangem os artigos e teses nacionais e internacionais.

\section{RESULTADOS E DISCUSSÃO}

O volume de artigos científicos e teses que abordam a gestão escolar nos últimos dez anos evidencia a importância que vem sendo dada a essa temática a partir de 2005. Após a promulgação da Constituição Federal/88 (BRASIL, 1988) e da LDB/96 (BRASIL, 1996), instrumentos de grande importância em nosso país para a gestão escolar, em diversas produções científicas, observa-se a crescente discussão sobre o tema, tornando relevante a análise dos aspectos quantitativos e qualitativos desta pesquisa. Em âmbito internacional, também se encontra um volume de produções significativo, pois, como já foi discutido no referencial teórico deste estudo, observa-se que ocorreu nas últimas décadas uma busca pela descentralização da gestão escolar em diversos países e que reformas educacionais vêm sendo implementadas.

Na Tabela 1, percebe-se que há uma média de seis produções nacionais por ano sobre gestão escolar. Dourado (2007) afirma que a discussão sobre políticas e gestão da educação no Brasil tem sido objeto de vários estudos no cenário nacional e internacional. Destaca que essa temática traz várias perspectivas, concepções e cenários complexos em disputa da ação política de diferentes atores e contextos institucionais influenciados por marcos regulatórios das agências 
e/ou organismos multilaterais. Nos estudos realizados pela presente pesquisa, observa-se que ocorreu uma pequena queda tanto nas publicações nacionais quanto nas internacionais após 2009, havendo um pequeno crescimento apenas em relação às teses nacionais. Compreende-se melhor esse fato nas afirmações de Dourado (2007), que defende a ideia de que a instituição da eleição de diretores como forma de provimento ao cargo de gestor escolar, difundida no Brasil pós anos 80, incentivou o debate sobre a temática da gestão escolar. Entretanto, nos anos 2000, iniciou-se um declínio no uso de eleições como forma de provimento, surgindo os concursos públicos, processos seletivos e o retorno da indicação técnica e política em diversas regiões do Brasil. Para Luporini, Martiniak e Marochi (2011), ainda é forte a cultura de indicação por parte do poder executivo, sendo essa prática uma forma de controle dos sistemas de ensino que tem grande capacidade de alcance às comunidades locais. Em uma pesquisa divulgada pelo Instituto Brasileiro de Geografia e Estatística (IBGE), denominada Pesquisa de Informações Básicas Municipais, realizada em 2014, observa-se que $74,4 \%$ dos diretores escolares da rede municipal de ensino no Brasil são escolhidos apenas com base na indicação política, ficando as outras formas de provimento, como eleição e concurso público, com apenas $25,6 \%$ do total de escolas. Esses dados mostram que as eleições como forma de provimento declinaram, o que pode ter desmotivado novas pesquisas sobre gestão escolar por parte de pesquisadores da área. Em relação ao quantitativo nacional e internacional, optou-se na presente pesquisa por levantar um maior volume de artigos nacionais, pois a gestão escolar no Brasil é o foco maior deste estudo; já os estudos internacionais são relevantes para que se faça um comparativo entre as temáticas pesquisadas no Brasil e no mundo, observando-se semelhanças no enfoque dado a elas.

TABELA 1

PUBLICAÇÕES NACIONAIS E INTERNACIONAIS

\begin{tabular}{|c|c|c|c|}
\hline TIPO DE TEXTO & 2005 até 2009 & 2010 até 2015 & TOTAL \\
\hline \multicolumn{4}{|l|}{ Brasil } \\
\hline Artigos científicos nacionais & 30 & 26 & 56 \\
\hline Teses no Brasil & 5 & 8 & 13 \\
\hline TOTAL DE PUBLICAÇÔES & 35 & 34 & 69 \\
\hline \multicolumn{4}{|l|}{ Outros países } \\
\hline $\begin{array}{l}\text { Artigos científicos } \\
\text { internacionais }\end{array}$ & 17 & 13 & 30 \\
\hline Teses internacionais & 2 & 0 & 2 \\
\hline TOTAL DE PUBLICAÇÔES & 19 & 13 & 32 \\
\hline
\end{tabular}

Fonte: Elaboração das autoras. 
Com relação ainda às publicações internacionais, identificaram-se 17 artigos científicos referentes a Portugal, Espanha, Canadá, Estados Unidos e Chile. Observou-se também que a média de publicações nos últimos anos é menor do que a média nacional, ficando em torno de três a cada ano. Embora se compreenda que essa é uma análise complexa, pois as publicações podem ser mais relevantes, não se teve acesso à base local de cada país, apenas às das bases de dados trabalhadas.

Com relação aos conteúdos abordados nas publicações, foi realizada a classificação dos dados em categorias, sendo definidas quatro categorias centrais e comuns às publicações.

\section{GESTÃO ESCOLAR DEMOCRÁTICA E AUTONOMIA}

As pesquisas dessa categoria abordam a gestão democrática instituída pela legislação atual, a organização das ações que desencadeiam a participação da comunidade escolar através da mobilização dos atores envolvidos (conselho escolar, grêmio estudantil e demais órgãos colegiados), o planejamento das ações, a tomada de decisões, as deliberações coletivas e individuais, os debates sobre processos de instituição da gestão democrática e/ou participativa nas escolas públicas. Foram encontradas diferentes vertentes dessa proposta, como a discussão sobre a introdução de modelos de administração dentro de um padrão mais empresarial em confronto com modelos mais voltados para a gestão, dentro de uma perspectiva mais democrática e de estratégias de participação coletiva. Nesses estudos, observa-se nas publicações nacionais as discussões sobre a instituição da gestão democrática na educação através da Constituição de 1988 (BRASIL, 1988), da LDB de 1996 (BRASIL, 1996) e dos Planos Nacionais, Estaduais e Municipais de educação. A discussão sobre o tema autonomia é sempre muito complexa nesses estudos, na maior parte dos quais se pode observar que o tipo de autonomia oferecida pelos órgãos responsáveis, como secretarias de educação, no caso a financeira e administrativa, não é a que atrai os membros da comunidade escolar e os teóricos. O debate está em torno de se conquistar uma autonomia pedagógica e do fato de que essa vem se apresentando nos sistemas educacionais brasileiros de forma centralizada, o que impede o crescimento e a identidade pedagógica de cada escola. Autores como Beraldo e Pelozo (2007) e Blasi e Falcão (2008) defendem que a gestão educacional requer a participação da sociedade através de mecanismos institucionais. Essa presença da comunidade nos órgãos institucionais torna-se fundamental para a efetivação da gestão democrática, ao mesmo tempo que contribui para que os sujeitos aprendam a assumir responsabilidades e a tomar decisões que lhes servirão como vivência para sua participação política na sociedade em que estão inseridos. Pesquisas internacionais como a de Aguilar (2009) e Alves e Varela (2012) trazem um debate maior sobre a descentralização da educação, em que há uma tendência ao empoderamento da comunidade 
escolar e ao aumento de suas responsabilidades ao mesmo tempo que se reduzem as responsabilidades do Estado. Esses estudos defendem a ideia de que a autonomia precisa ser trabalhada e incentivada nas escolas, nas quais será construída uma relação escola-comunidade, que pode ser efetivada através de estratégias de implementação que irão gerar a autonomia organizacional e pedagógica das escolas.

\section{GESTÃO, GERÊNCIA E QUALIDADE DA EDUCAÇÃO}

A segunda categoria trata das questões relacionadas à administração escolar, à forma de gerir a escola e ao uso dos recursos financeiros enviados para a escola (Plano de Desenvolvimento da Escola - PDE Escola, Programa Dinheiro Direto na Escola - PDDE, Mais Educação e outros). Trata também das formas de avaliação internas e externas da escola, do Exame Nacional do Ensino Médio (Enem), do Índice de Desenvolvimento da Educação Básica (Ideb) e de outras avaliações estaduais e municipais. Algumas pesquisas, como as de Veloso, Abrantes e Craveiro (2011), defendem que a avaliação pode tanto contribuir para a formação de um modelo de escola mais eficaz, igualando as escolas em termos de parâmetros de avaliação, quanto pode ter um efeito segregador das escolas, em função dos resultados da avaliação virem a se tornar uma forma competitiva, transformando-se em rankings de escolas. Discute-se nos estudos analisados o sucesso da escola e as formas de gestão escolar. As políticas públicas voltadas para a avaliação e sua influência sobre a gerência ou ingerência na escola, que determina ou não as estratégias de administração escolar. A coexistência do discurso da democratização da gestão escolar com práticas avaliativas que se apoiam numa gerência mais voltada para resultados do que para ações consistentes. A participação da comunidade na gestão como um dos principais fatores de melhoria da qualidade da educação nas escolas também é discutida nessa categoria, assim como o compromisso, o envolvimento de todos no projeto pedagógico da escola e no cotidiano, em que se compartilham decisões sem autoritarismo. A avaliação institucional também é objeto de discussão em algumas pesquisas analisadas, nas quais se traz à tona o importante papel que esse tipo de avaliação exerce numa verdadeira gestão democrática da escola, pois, através dela, a escola e a comunidade em geral param para se ver, se enxergar e repensar seu projeto pedagógico. Os estudos dessa categoria focalizam, portanto, o financiamento, a gestão escolar e a qualidade da educação básica, trazendo a relação entre eles. Buscam também identificar os fatores atinentes ao financiamento e à gestão da educação que influenciam a dinâmica administrativo-pedagógica das unidades escolares, discutem a eficiência da gestão como possível fator que vem a influenciar a dinâmica escolar, refletindo positivamente na qualidade da educação. 


\section{PERFIL DO DIRETOR ESCOLAR, FORMAÇÃO \\ E REESTRUTURAÇÃO DA FUNÇÃO}

Na terceira categoria, apresentam-se os estudos sobre o perfil do diretor escolar dentro da reestruturação ocorrida na função nas últimas décadas, discutem-se as competências necessárias, a formação exigida e mais adequada, e os novos desafios trazidos a essa função. A categoria apresenta também a discussão do conceito de ser um "bom" gestor pelos atores da escola. As formas de liderança para a nova perspectiva que surge com a implantação da gestão democrática também são objeto dos estudos analisados, assim como: as dificuldades do gestor no papel de implementador das políticas públicas para educação na escola e do projeto político-pedagógico; o novo modelo de diretor que exige um perfil mais democrático e as dificuldades de elaboração desse modelo; a formação inicial exigida pela lei e os cursos de formação continuada que reelaboram o perfil do gestor escolar; as diversas dimensões de competências exigidas do gestor - pedagógica, técnica e política. Por fim, coloca-se em discussão, em alguns estudos, a reestruturação da função a partir da instituição do princípio da gestão democrática na Constituição (BRASIL, 1988) e na nova LDB (BRASIL, 1996) e das mudanças ocorridas através das exigências legais, em países europeus e americanos, quanto à descentralização nas escolas. Nos estudos de Cattonar (2006), Paro $(2009,2010)$ e Silva (2009), compreende-se que, na atualidade, existe uma orientação para uma direção escolar que acredite na educação em sua radicalidade, contemplando sua especificidade como processo pedagógico e sua dimensão democrática. Esses autores defendem que o gestor educacional deve gerir a escola em conjunto com a comunidade escolar, buscando atender às suas necessidades. Dessa forma, o diretor precisa desenvolver suas competências dentro das novas exigências da reestruturação da função. Cattonar (2006) apresenta também um estudo interessante no qual apresenta um levantamento teórico de autores que discutem a reestruturação da função na Europa, onde em diversos países, mais do que um bom gestor, o diretor deve ser também uma espécie de "animador pedagógico" na busca dos indicadores da política pedagógica da sua escola e, ao mesmo tempo, um "agente de mudança" do sistema educacional vigente.

\section{FORMAS DE ESCOLHA DE DIRETORES NAS ESCOLAS}

A última categoria trata das modalidades de escolha de diretores e das implicações de cada uma, dos limites que interpõem essas modalidades, do levantamento histórico sobre o provimento do cargo/ função de diretor escolar, da influência da forma de provimento na gestão democrática da escola e na qualidade da educação. Também se discutem, nos estudos analisados, as interfaces ocorridas através das formas de escolha e o papel do diretor, as diversas funções que o diretor exerce dentro da escola: administrativa, financeira, pedagógica, gestão 
de recursos humanos. Muitos teóricos defendem de forma veemente a eleição como forma democrática e que propicia a participação da comunidade; outros questionam a validade de cada modalidade, apresentando aspectos positivos e negativos. A maior parte concorda que alguma forma mista em que haja a participação da comunidade em forma de conselho seja a melhor opção. Autores como Carvalho (2012) e Abdian, Hojas e Oliveira (2012) acreditam que a participação dos sujeitos da escola nas decisões e na organização escolar é um dos aspetos que configuram a gestão democrática. Existem, de um lado, as diretrizes das políticas públicas voltadas para a cobrança das prestações de contas e controle econômico e, do outro, o crescimento da busca da participação efetiva da comunidade na escola, através da eleição de diretores, dos órgãos colegiados e de uma experiência democrática.

\section{TABELA 2}

DISTRIBUIÇÃO DE TRABALHOS POR CATEGORIA DE ANÁLISE - 2005-2015

\begin{tabular}{|c|c|c|c|c|c|c|}
\hline \multirow{3}{*}{ Categorias de análise } & \multicolumn{6}{|c|}{ Fontes nacionais e internacionais } \\
\hline & \multicolumn{2}{|c|}{ Teses } & \multicolumn{2}{|c|}{ Artigos } & \multirow[b]{2}{*}{ Total } & \multirow[b]{2}{*}{$\%$} \\
\hline & № & $\%$ & $\mathrm{~N}^{\mathrm{a}}$ & $\%$ & & \\
\hline $\begin{array}{c}\text { Gestão escolar democrática e } \\
\text { autonomia }\end{array}$ & 4 & $26 \%$ & 36 & $42 \%$ & 40 & $40 \%$ \\
\hline $\begin{array}{l}\text { Gestão, gerência e qualidade da } \\
\text { educação }\end{array}$ & 6 & $40 \%$ & 25 & $29 \%$ & 31 & $30 \%$ \\
\hline $\begin{array}{l}\text { Perfil do diretor escolar, formação } \\
\quad \text { e reestruturação da função }\end{array}$ & 4 & $26 \%$ & 23 & $27 \%$ & 27 & $27 \%$ \\
\hline $\begin{array}{l}\text { Formas de escolha de diretores } \\
\text { nas escolas }\end{array}$ & 1 & $8 \%$ & 2 & $2 \%$ & 3 & $3 \%$ \\
\hline Total & 15 & $100 \%$ & 86 & $100 \%$ & 101 & $100 \%$ \\
\hline
\end{tabular}

Fonte: Elaboração das autoras.

Analisando as categorias identificadas nas produções, observa-se que a 1 e a 2 são as que apresentam maior número de trabalhos, respectivamente 40 e 30 por cento do total dos documentos analisados. Em todas as categorias de análise, predominam os artigos em detrimento das teses. A categoria com menor percentual de publicações é a quatro, na qual foram analisados trabalhos sobre a escolha de diretores. Essa é uma temática que teve uma ascensão a partir da década de 1980 e uma queda no século XXI, quando as redes públicas de ensino passaram a utilizar o concurso público ou o processo seletivo como forma mais comum de escolha, e as eleições foram deixadas de lado. Porém o tema volta a ser foco de discussão, ainda de maneira tímida, nos últimos três anos. Outra justificativa para o número reduzido de publicações sobre 
Formas de escolha de diretores nas escolas é que essa temática insere-se como subtema, estando presente quando se fala da Gestão, do perfil e da reestruturação da função, mas não se apresentando como tema principal, e sim como complementar em outros debates. Percebe-se também que, nas teses analisadas, destacam-se as discussões sobre Gestão, gerência e qualidade da educação e, em segundo lugar, sobre Gestão democrática e autonomia, empatada com a discussão sobre o Perfil do diretor. Nas pesquisas nacionais, prevalecem as discussões em torno das mudanças ocorridas após a promulgação da Constituição de 88 (BRASIL, 1988) e da LDB de 96 (BRASIL, 1996), especialmente sobre gestão democrática, descentralização, autonomia e participação coletiva.

Nas análises realizadas nos artigos internacionais, percebe-se a valorização dos temas sobre Estratégias de gestão e competências do diretor escolar em artigos de língua inglesa e de Gestão participativa e democrática nos oriundos de Portugal e países de língua espanhola. Prevalece uma discussão mais técnica no primeiro caso e uma mais política no segundo caso, o que é uma característica compreensível, levando-se em conta que, no primeiro caso, há uma preocupação mais técnica e formal na administração escolar e, nos outros países, mais político-administrativa, por questões históricas relacionadas à trajetória da educação local. É importante destacar que muitos dos artigos são adaptações de capítulos de teses e dissertações, evidenciando a liberdade dos autores em dar destaque aos aspectos conceituais de suas pesquisas.

Em relação à metodologia das pesquisas analisadas, observou-se que prevalecem as pesquisas qualitativas sobre as quantitativas. Na base das pesquisas qualitativas estão a pesquisa bibliográfica e a documental no maior percentual dos trabalhos, porém muitos não trazem uma discussão empírica, apenas conceitual com base literária. Nas pesquisas que trazem uma discussão empírica, tanto qualitativas como quantitativas, observa-se o uso de análise de entrevistas, pesquisa no cotidiano, aplicação de questionários, cases, pesquisa survey e análise de relatórios de dados. Em geral, no resultado dessas pesquisas, observa-se uma preocupação da comunidade escolar com a participação coletiva e as formas de gerir a instituição escolar. Os participantes da pesquisa ou os modelos de gestão escolar apresentados demonstram preocupação com a qualidade da educação e a influência da gestão escolar sobre esse aspecto.

Nas pesquisas das categorias Gestão escolar democrática e autonomia e Gestão, gerência e qualidade da educação, o uso de revisão de literatura é mais relevante do que a utilização de instrumentos de coleta para análise empírica, prevalecendo assim um estudo mais conceitual e teórico do tema. Já no caso das categorias Formas de escolha de diretores nas escolas e Perfil do diretor escolar, formação e reestruturação da função percebe-se ainda o uso constante de pesquisa bibliográfica, mas boa parte dos estudos utiliza-se de uma percepção empírica dos fatos, trazendo as vo- 
zes dos envolvidos no processo de eleição de diretores e na necessidade de um perfil de gestor mais adequado às novas exigências da educação no século XXI. Essas vozes destacam a necessidade de um gestor mais democrático, mais bem formado profissionalmente, e de maior apoio para a gestão escolar por parte dos órgãos responsáveis.

\section{CONSIDERAÇÕES FINAIS}

Gestão escolar é um conceito construído historicamente, impregnado de valores e significados específicos trazidos dentro de um contexto político e educacional, os quais vêm sendo construídos e reconstruídos nos últimos anos. A literatura discute que inicialmente esse conceito estava direcionado aos aspectos mais administrativos da função e que, com o passar dos tempos, de acordo com as mudanças sociais e históricas reafirmadas pela legislação em vigor, passou a buscar o teor mais pedagógico e político da palavra.

O crescimento das pesquisas nos últimos anos sobre gestão escolar no Brasil, com ênfase na gestão escolar democrática, vem no bojo da instituição da Constituição de 1988 (BRASIL, 1988) e da Lei de Diretrizes e Bases da Educação publicada em 1996 (BRASIL, 1996), que a instituíram como princípio da educação. Nos estudos internacionais, os caminhos não são muito diferentes. Pode-se perceber uma preocupação em discutir o tipo de autonomia forjado às escolas e a autonomia que a escola deseja, discussão essa observada em âmbito nacional e internacional. Os pesquisadores demonstram preocupação em compreender os rumos tomados pelas políticas educacionais no final do século XX e o encaminhamento dado a elas na comunidade escolar no início do século XXI.

Através da coletânea de pesquisas aqui apresentadas, buscou-se identificar a existência ou não de lacunas na literatura sobre o tema em estudo, realizando uma análise quantitativa das publicações dos últimos dez anos e uma análise qualitativa sobre a evolução do conceito de gestão escolar, observando-se também o formato das análises metodológicas aplicadas. Observou-se que, dentro do universo pesquisado, ocorreu crescimento quantitativo durante os primeiros anos da pesquisa (2005-2009). Entretanto, houve um pequeno declínio nos anos finais (2010-2015).

Pode-se perceber que existem algumas lacunas ainda a serem preenchidas com novos trabalhos e pesquisas, especialmente quanto a assuntos relacionados à formação, às competências, à identidade e à qualidade que se exige do trabalho do mentor dessa gestão democrática: o diretor ou gestor escolar. Outro ponto detectado foi o inexpressivo número de pesquisas de cunho empírico. A ausência de experimentos pode ser indício da fragilidade do meio a ser pesquisado e a sua presen- 
ça poderia enriquecer o conhecimento a respeito da gestão escolar e de sua estruturação no cotidiano da escola.

Um fator positivo encontrado foi o predomínio de pesquisas que relacionam a gestão escolar com a necessidade de uma gestão democrática, especialmente nas pesquisas nacionais, nas quais se discute a importância de se fazer cumprir o que a legislação determina sobre essa temática. O conceito de gestão escolar é socialmente construído e reconstruído de acordo com a evolução histórica e das políticas educacionais em pauta. Assim, a noção de gestão democrática traz diversos significados e possibilidades a serem discutidos dentro do contexto político, econômico e cultural da sociedade em geral e do ambiente escolar em suas particularidades.

A presente pesquisa apresenta algumas limitações. Ferreira (2002) explica que existem inúmeras maneiras de se fazer um estado da arte, pois cada pesquisador tem um olhar diferente sobre os fenômenos analisados. As categorias aqui apresentadas não são únicas e acredita-se que, em futuros estudos, possam surgir categorias diferentes das propostas neste trabalho. Também se entende como uma limitação o fato de serem contempladas apenas algumas bases de dados e não a totalidade existente, especialmente na literatura internacional. Com isso, pode-se afirmar que não foram observadas todas as pesquisas de cunho científico, uma vez que: existem periódicos que ainda não se encontram no formato on-line; as bases selecionadas para o estudo, apesar de serem representativas para o campo da educação, não abarcam todas as revistas disponíveis eletronicamente. Entretanto, as limitações aqui encontradas não eliminam as contribuições oferecidas pelo estudo, para o qual foi realizado um trabalho intenso de pesquisa com mais de 100 publicações, nacionais e internacionais, com textos em português, espanhol e inglês, com a leitura na íntegra da maior parte dos textos selecionados. Essas limitações alertam que outros olhares e formas de se entender o mesmo fenômeno podem existir sobre o mesmo corpus. Isso reforça a necessidade de mais estudos envolvendo a gestão escolar e as suas relações e contribuições com a melhoria da qualidade da educação e, consequentemente, da sociedade em geral.

O período examinado configurou uma fase da produção científica na área educacional constituída de ações diversificadas em relação às políticas públicas que enriqueceu a discussão da temática em estudo. As publicações analisadas apontam para uma preocupação atual em promover o debate sobre a gestão escolar visando a estabelecer formas de gestão que permitam a instituição da participação da comunidade na escola. Os trabalhos que compõem esta revisão sugerem um cenário rico de discussão voltada para a reestruturação da função do gestor e do espaço escolar em sua forma mais democrática, sempre em busca da qualidade da educação. 


\section{REFERÊNCIAS}

ABDIAN, Graziela Zambão; HOJAS, Viviane Fernanda; OLIVEIRA, Maria Eliza Nogueira. Formação e função e formas de provimento do cargo do gestor escolar: as diretrizes da política educacional e o desenvolvimento teórico da administração escolar. Educação Temática Digital, Campinas, v. 14, n. 1, p. 399-419, 2012.

AGUILAR, Márcia Angela de S. Conselhos escolares, espaço de cogestão da escola. Revista Retratos da Escola, Brasília, v. 3, n. 4, p. 173-183, jan.jjun. 2009.

ALVES, Mariana G.; VARELA, Teresa. Construir a relação escola-comunidade educativa: uma abordagem exploratória no concelho de Almada. Revista Portuguesa de Educação, v. 25, n. 2, p. 31-61, 2012

ANDRADE, Belisário H. C. L. Dicionário de sinônimos da língua portuguesa. Elfez, 2001.

BARDIN, Laurence. Análise de conteúdo. Lisboa: Edições Setenta, 2011. 226 p.

BERALDO, Fernando; PELOZO, Rita de Cássia B. A gestão participativa na escola pública: tendências e perspectivas. Revista Científica Eletrônica de Pedagogia, Garça, v. 5, n. 10, jul. 2007.

BLASI, Jacqueline de; FALCÃO, Sandra. Gestão participativa na escola. Revista Sinergia, São Paulo, v. 9, n. 1, 2008.

BORDIGNON, Genuíno; GRACINDO, Regina Vinhaes. Gestão da educação: o município e a escola. In: FERREIRA, Naura Syria Carapeto; AGUIAR, Márcia Ângela da S. (Org.). Gestão da educação: impasses, perspectivas e compromissos. São Paulo: Cortez, 2000. p. 147-176.

BORGES, André. Lições de reformas da gestão educacional: Brasil, EUA e Grã-Bretanha. São Paulo em Perspectiva, São Paulo, v. 18, n. 3, p. 78-89, jul./set. 2004.

BRASIL. Constituição da República Federativa do Brasil. Brasília, DF: Senado Federal, 1988.

BRASIL. Ministério da Educação. Lei n. 9.394/96, 20 dezembro de 1996. Estabelece a Lei de Diretrizes e Bases da Educação Nacional. Brasília: MEC, 1996.

BURAK, Dalila Maria Antoneche; FLACK, Simone de Fátima. Concepções de gestão escolar presentes no trabalho do diretor nas escolas municipais em Ponta Grossa-PR. In: JORNADA NACIONAL DO HISTEDBR, 10., 2011, Ponta Grossa. Anais... Ponta Grossa: UEPG, 2011.

CARDOSO, Tereza; ALARCÃO, Isabel; ANTUNES, Celorico J. Revisão da literatura e sistematização do conhecimento. Porto: Porto, 2010.

CARVALHO, Elma Júlia G. de. Gestão escolar: da centralização à descentralização. Cadernos de Pesquisa em Educação, Vitória, a. 9, v. 18, n. 36, p. 39-59, jul./dez. 2012.

CATTANI, Antonio David; HOZLMANN, Lorena (Org.). Dicionário do trabalho e tecnologia. 2. ed. Porto Alegre: Zouk, 2011.

CATTONAR, Branka. Evolução do modo de regulação escolar e reestruturação da função de diretor de escola. Educação em Revista, n. 44, p. 185-208, 2006.

CUNHA, Luiz. A. Educação, Estado e democracia. São Paulo: Cortez; Niterói: EDUFF; [Brasília, DF]: Flacso, 1991.

DOURADO, Luís Fernando. Políticas e gestão da educação básica no Brasil: limites e perspectivas. Educação e Sociedade, Campinas, v. 28, n. 100, p. 921-946, out. 2007.

FERREIRA, Naura S. C. Violência e paz: a exigência de novas políticas e ações integradas. In: Violência e indisciplina na escola. Anais do XI Colóquio da AFIRSE. Lisboa: Universidade de Lisboa, 2002.

GARAY, Angela. Gestão. In: CATTANI, Antonio David; HOZLMANN, Lorena (Org.). Dicionário de trabalho e tecnologia. 2. ed. Porto Alegre: Zouk, 2011.

GRACINDO, Regina V.; WITTMANN, Lauro Carlos. (Org.). 0 estado da arte em política e administração da educação no Brasil: 1991-1997. Campinas: Autores Associados, 2001. 272p.

INSTITUTO BRASILEIRO DE GEOGRAFIA E ESTATISTICA - IBGE. Perfil dos estados e dos municípios brasileiros: cultura: 2014. Rio de Janeiro: IBGE, 2015. 126 p. 
LIBÂNEO, José Carlos. A organização e a gestão da escola: teoria e prática. Goiânia: Alternativa, 2007.

LÜCK, Heloisa. Gestão educacional: uma questão paradigmática. Petrópolis: Vozes, 2007.

LUPORINI, Teresa J.; MARTINIAK, Vera Lúcia; MAROCHI, Zélia Maria L. Eleição e formação de diretores de escolas municipais: a legislação e as práticas da rede municipal de ensino de Ponta Grossa. Revista HISTEDBR, Campinas, n. 43, p. 214- 222, set. 2011.

PARO, Vítor Henrique. Estrutura da escola e educação como prática democrática. In: CORREA, Bianca C.; GARCIA, Teise O. (Org.). Políticas educacionais e organização do trabalho na escola. São Paulo: Xamã, 2008. p. 11-38.

PARO, Vitor Henrique. Elección de directores escolares en Brasil: un instrumento democrático. Docencia, Santiago de Chile, v. 14, n. 39, p. 90-100, dez. 2009.

PARO, Vitor Henrique. A educação, a política e a administração: reflexões sobre a prática do diretor de escola. Educação e Pesquisa, São Paulo, v. 36, n. 3, p. 763-778, set./dez. 2010.

PEREIRA, Gilson R. de M.; ANDRADE, Maria da Conceição L. de. A construção da administração da educação na RBAE (1983-1996). Educação \& Sociedade, Campinas, v. 26, n. 93 p. 1393-1411, set./dez. 2005

ROCHA, Roberto. A gestão descentralizada e participativa das políticas públicas no Brasil. Revista Pós Ciências Sociais, São Luis, v. 1, n. 11, p. 41-57, 2009.

SANDER, Benno. Administração da Educação no Brasil: genealogia do conhecimento. Brasília: Liber Livro, 2007.

SANTOS FILHO, José Camilo dos. Democracia institucional na escola: discussão teórica. Revista de Administração Educacional, Recife, v. 1, n. 2, p. 41-101, jan./jun. 1998.

SILVA, Eliene Pereira da. A importância do gestor educacional na instituição escolar. Revista Conteúdo, Capivari, v. 1, n. 2, p. 67- 83. jul./dez. 2009.

SOUZA, Angelo Ricardo de. Os caminhos da produção científica sobre Gestão Escolar no Brasil. RBPAE, São Paulo, v. 22, n. 1, p. 13-39, 2006.

VASCONCELLOS, Celso dos S. Coordenação do trabalho pedagógico - do projeto político-pedagógico ao cotidiano da sala de aula. 11. ed. São Paulo: Libertad, 2009.

VELOSO, Luísa; ABRANTES, Pedro; CRAVEIRO, Daniela. A avaliação externa das escolas como processo social. Educação, Sociedade e Culturas, Porto, n. 33, p. 69-88, 2011.

WHITTY, Geoff; POWER, Sally Anne. Marketization and privatization in mass education systems. International Journal of Educational Development, n. 20, p. 93-107, 2000.

Recebido em: 05 MARÇO 2018 | Aprovado para publicação em: 10 ABRIL 2018 